BMJ Open

Sport \&

Exercise

Medicine

\section{Knee osteoarthritis in traumatic knee symptoms in general practice: 6-year cohort study}

To cite: Kastelein M, Luijsterburg PAJ, Koster IM, et al. Knee osteoarthritis in traumatic knee symptoms in general practice: 6-year cohort study. BMJ Open Sport Exerc Med 2016;2: e000153. doi:10.1136/ bmjsem-2016-000153

- Prepublication history for this paper is available online To view these files please visit the journal online (http://dx.doi.org/10.1136/ bmjsem-2016-000153).

Accepted 2 August 2016

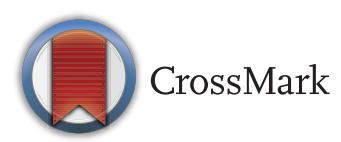

${ }^{1}$ Department of General Practice, Erasmus MC, University Medical Center Rotterdam, Rotterdam, The Netherlands

${ }^{2}$ Department of Radiology, Albert Schweitzer Hospital, Dordrecht, The Netherlands ${ }^{3}$ Department of Orthopedics, Erasmus MC, University Medical Center Rotterdam, Rotterdam, The Netherlands ${ }^{4}$ Department of Radiology, Maasstad Hospital,

Rotterdam, The Netherlands ${ }^{5}$ Department of Radiology, Erasmus MC, University Medical Center Rotterdam, Rotterdam, The Netherlands

Correspondence to Pim AJ Luijsterburg; p.luijsterburg@erasmusmc.nl

\section{ABSTRACT}

Aim: To identify degenerative knee abnormalities using $\mathrm{MRI}$ and radiography 6 years after knee trauma, their relation with persistent knee symptoms and baseline prognostic factors.

Methods: Adults (18-65 years) with incident traumatic knee symptoms visiting their general practitioner were followed up for 6 years and underwent baseline MRI and 6-year follow-up MRI and radiography. Logistic regression was used to analyse associations between various degenerative abnormalities on 6-year MRI and radiography, persistent knee symptoms and baseline prognostic factors for knee osteoarthritis (OA) on 6-year MRI.

Results: On 6-year radiography, $60 \%$ of patients showed no OA, 28\% showed OA with

Kellgren\&Lawrence (K\&L) grade 1 and $13 \%$ showed with $\mathrm{K} \& \mathrm{~L}$ grade 2 . On 6 -year MRI, $55 \%$ of patients showed cartilage defect(s), 45\% showed osteophyte (s), 36\% showed subchondral cyst(s), 40\% showed bone marrow oedema, $21 \%$ showed meniscal subluxation, $83 \%$ showed meniscal degeneration, $11 \%$ showed effusion and $11 \%$ showed a Baker's cyst. Of these, most were significantly related with 6-year radiographic $\mathrm{K} \& \mathrm{~L}$ grade, while only lateral cartilage defect(s), medial osteophyte(s) and medial meniscal subluxation were significantly related with persistent knee symptoms. $32 \%$ of patients showed new onset or progressive knee OA on 6-year MRI, for which age, history of non-traumatic knee symptoms and bone marrow oedema at baseline were independent prognostic factors.

Conclusions: Degenerative knee abnormalities on $\mathrm{MRI}$ are related to the K\&L score; however, not all abnormalities are reflected in clinical outcome. Age, history of non-traumatic knee symptoms and bone marrow oedema predict knee OA 6 years after knee trauma, present in $32 \%$ of the patients.

\section{INTRODUCTION}

The incidence of traumatic knee symptoms in Dutch general practice is $\sim 5.3$ per 1000 patients per year. ${ }^{1}$ Our earlier study showed that $17 \%$ of these patients reported persistent knee symptoms at 1-year follow-up. ${ }^{2}$ Because knee trauma is a risk factor for knee

\section{What are the new findings?}

- Degenerative knee abnormalities on MRI are related to osteoarthritis $(O A)$ on X-ray.

- Age, history of non-traumatic knee symptoms and bone marrow oedema on MRI predict knee OA 6 years after knee trauma.

How might it impact on clinical practice in the near future?

Clinicians should be aware of the occurrence of knee $O A$ in patients after knee trauma, and check for a history of non-traumatic knee symptoms and bone marrow oedema on initial MRI.

osteoarthritis $(\mathrm{OA})^{3-6}$ and knee $\mathrm{OA}$ is a chronic disorder with a major burden, ${ }^{7}$ knowledge on prognostic factors for knee $\mathrm{OA}$ in patients with traumatic knee symptoms could be helpful to diminish this burden of knee $\mathrm{OA}$ in these patients in the future.

From primary care, one study showed progression of knee $\mathrm{OA}$ in $15 \%$ of the patients with existing knee OA, new degenerative changes in $26 \%$ of the patients with no knee OA at baseline. ${ }^{8}$ From secondary care, there is evidence that about $50 \%$ of patients with a traumatic meniscal lesion or an anterior cruciate ligament lesion develop knee $\mathrm{OA}$ at a younger age than expected. ${ }^{9}$ Bone marrow oedema may also be a risk factor for structural deterioration and progression of knee OA in secondary care. ${ }^{1011}$

Research on developing knee OA in patients with traumatic knee symptoms is complicated because it is difficult to diagnose knee OA in an early stage. ${ }^{12} \mathrm{MRI}$ is the best available technique for the detection of early osteoarthritic changes. ${ }^{13}$ Although a consensus-based definition for OA has been published, it has not yet been validated. ${ }^{14}$ 
This study assessed the (1) frequency of degenerative knee abnormalities in these patients on radiography and MRI at 6-year follow-up, (2) the relationship between findings on MRI and radiography, (3) their correlation with persistent knee symptoms at 6-year follow-up and (4) their relationship with prognostic factors at baseline (including MRI findings).

\section{METHOD}

\section{Design and patients}

The present study is a part of a prospective, observational cohort study in which 1068 consecutive patients visiting their general practitioner (GP) with a new episode of knee symptoms followed up for 6 years. ${ }^{15}$ New knee symptoms were defined as episodes of symptoms presented to the GP for the first time. Traumatic knee symptoms were defined as those caused by a sudden impact.

Patients were eligible for the present study if they were aged 18-65 years, had consulted their GP with traumatic knee symptoms within 5 weeks after the trauma and signed informed consent for an MRI of their knee. Exclusion criteria were knee symptoms that required urgent medical attention (eg, fractures), patients with malignancies, neurological disorders or systematic musculoskeletal diseases (eg, rheumatoid arthritis), as well as patients with insufficient understanding of the Dutch language.

\section{Data collection}

Patients filled out a questionnaire at baseline, and at 1-year and 6-year follow-up. The questionnaires provided data on demographics, on knee symptoms (eg, knee pain assessed on an 11-point $[0=$ no pain and $10=$ unbearable pain] numeric rating scale (NRS), and knee pain and function assessed with the Lysholm Knee Scoring Scale) ${ }^{16-18}$ and on treatment. For the Lysholm score, higher scores represent better function/outcome.

In addition, the questionnaires at 1-year and 6-year follow-up also provided data on experienced recovery measured on a 7-point Likert scale (ranging from 'completely recovered' to 'worse than ever').

Persistent knee symptoms were defined as knee symptoms that were 'slightly improved', 'not changed', 'slightly worsened', 'much worsened' or 'worse than ever'.

Clinically important recovery was defined as knee symptoms that were 'completely recovered' or 'much improved'.

A standardised physical examination was carried out by a trained physiotherapist at baseline and at 1-year follow-up; this consisted of inspection (alignment and joint effusion), palpation (temperature, collateral ligaments and joint line tenderness), assessment of joint effusion, passive range of motion in flexion and extension, meniscal tests and knee stability tests. ${ }^{19} 20$

MRI of the knee was performed within 3-6 weeks of the trauma and was repeated after 6 years. At baseline, a
1.0 $\mathrm{T}$ whole-body MRI unit was used, whereas at 6-year follow-up, MRI was performed on a $1.5 \mathrm{~T}$ whole-body MRI scanner. In both examinations, we used a dedicated knee coil and an MRI protocol that consisted of sagittal T1, T2 and proton density-weighted fast spin-echo sequences, coronal $\mathrm{T} 2 *$-weighted gradient echo and fatsuppressed T2-weighted fast spin-echo sequences, and an axial proton density-weighted fast spin-echo sequence.

The initial and follow-up MRI examinations were independently evaluated by two radiologists for the presence of degenerative abnormalities of the femorotibial joint of the index knee, according to the Knee Osteoarthritis Scoring System (KOSS). ${ }^{21}$

In case of discrepancies, consensus was reached through discussion. We defined OA of the femorotibial joint of the index knee on MRI according to the definition described by Hunter et al. ${ }^{14}$ In addition to degenerative abnormalities, we also assessed the presence of ligamentous lesions, meniscal lesions and bone marrow oedema on MRI.

To reflect clinical practice, the reports and the images of the initial MRI examination were available when evaluating the follow-up MRI. In this observational cohort study, the treating GP was not informed of the MRI findings unless the findings required immediate treatment.

At 6-year follow-up only, an anterior posterior radiograph of the index knee was made. To assess radiographic knee OA at 6-year follow-up, two trained readers independently scored the radiograph for OA according to the classical K\&L grading $(0-4)$ system, ${ }^{22}$ unaware of the clinical status of the patients.

\section{Statistical analysis}

ORs were used to calculate the association between the various degenerative abnormalities on the 6-year MRI and the 6-year K\&L score. ORs were also used to calculate the relation between the various degenerative abnormalities on the 6-year MRI and persistent knee symptoms at 6-year follow-up.

Univariate logistic regression analysis was performed to determine which baseline variables from history taking and MRI are associated with new onset knee OA or progression of existing knee OA seen on the 6-year MRI. The baseline variables used as eligible prognostic factors for the univariate analysis were based on literature $^{23}$ and clinical relevance. The eligible factors were divided into three domains: patient characteristics, complaint characteristics and MRI findings. Imputation of missing data was carried out by multiple imputation, creating a total of five imputed databases. ${ }^{24-26}$

The factors of each domain showing a univariate association with knee OA seen on the 6-year MRI in at least 3 of 5 imputed databases $(\mathrm{p} \leq 0.20)$ were analysed in a multivariable (backward) logistic regression model (entry 0.10 , removal 0.20 ). 
If a factor of one domain was selected in at least 3 of 5 imputed databases in the multivariate analysis, it was included in the final model (enter method).

Analyses were performed with SPSS V.17.02 (SPSS, Chicago, Illinois, USA).

\section{RESULTS}

\section{Study population}

Table 1 shows the baseline characteristics of the 134 patients included in the study. Their mean age was 40.3 (SD 12.2) years and 55.2\% was men. MRI of the knee was normal in 15 patients $(11.2 \%)$. At baseline, the mean knee pain severity on the NRS was 4.8 (SD 2.4) and the mean Lysholm knee function score was 63.7 (SD 19.8).

After 6 years, 78 patients $(58.2 \%)$ were still available for follow-up (table 1). The patients lost to follow-up showed no differences compared with those available at 6-year follow-up regarding baseline variables. Reasons for no longer participating at 6-year follow-up were lack of time and/or lack of interest $(n=18,32.1 \%)$, and being untraceable due to change of address and/or telephone number $(\mathrm{n}=27,48.2 \%)$; in addition, 2 patients $(3.6 \%)$ had died during the follow-up period and for 9 patients $(16.1 \%)$ no reason was available.

\section{Clinical outcome}

At 6-year follow-up, $26(33.3 \%)$ of the 78 available patients reported persistent knee symptoms; these 26 patients reported a mean knee pain severity of 3.7 (SD 2.0) and a mean Lysholm knee score of 68.4 (SD 16.9).

None of the diagnoses on baseline MRI (table 1) was significantly associated with persistent knee symptoms at 6-year follow-up (data not shown).
Having persistent knee symptoms at 1-year follow-up was significantly associated with reported persistent knee symptoms at 6-year follow-up (OR 5.54, 95\% CI 1.44 to 20.32).

During the 6-year follow-up, $11(14.1 \%)$ of the 78 patients underwent surgery of the knee; of these 11 patients, $6(54.5 \%)$ reported persistent knee symptoms at 6-year follow-up.

\section{Degenerative abnormalities of the knee}

The K\&L score for knee OA on the 6-year radiograph is shown in table 2. Of the 47 available patients, 28 $(59.6 \%)$ showed no radiographic knee OA (grade 0), 13 $(27.7 \%)$ showed grade 1 knee OA and 6 patients $(12.8 \%)$ showed grade 2 knee OA. There were no patients with advanced stage OA (K\&L grade 3 or 4 ).

The degenerative abnormalities on the 6-year MRI (based on the KOSS scoring system) are also reported in table 2. Of the 47 patients, $26(55.3 \%)$ showed cartilage $\operatorname{defect}(\mathrm{s}), 21$ (44.7\%) osteophyte(s), 17 (36.2\%) subchondral cyst(s), 19 (40.4\%) bone marrow oedema, 10 $(21.3 \%)$ meniscal subluxation, 39 (83.0\%) meniscal degeneration, $5(10.6 \%)$ joint effusion and 5 patients $(10.6 \%)$ showed a Baker's cyst. These degenerative changes on the 6-year MRI were significantly more frequently reported in the medial than in the lateral compartment of the femorotibial joint (table 2).

Most of the degenerative abnormalities on the 6-year MRI showed a significant relation with the K\&L score on the 6-year radiograph. Only lateral subchondral cyst, lateral bone marrow oedema, medial meniscal degeneration, effusion and Baker's cyst were not significantly related (table 2). Only a few of the degenerative abnormalities on the 6-year MRI (ie, lateral cartilage defect(s), medial osteophyte(s) and medial meniscal subluxation)

Table 1 Baseline characteristics of the total group of patients and those available at 6-year follow-up

\begin{tabular}{|c|c|c|c|}
\hline Baseline characteristic & $\begin{array}{l}\text { All included } \\
\text { patients at } \\
\text { baseline }(n=134)\end{array}$ & $\begin{array}{l}\text { Available at 6-year } \\
\text { follow-up }(n=78)\end{array}$ & $\begin{array}{l}\text { Agreed to 6-year } \\
\text { MRI and } \\
\text { radiography }(n=47)\end{array}$ \\
\hline \multicolumn{4}{|l|}{ General } \\
\hline Age in years, mean $\pm S D$ & $40.3 \pm 12.2$ & $41.6 \pm 11.2$ & $43.7 \pm 10.5$ \\
\hline Male, n (\%) & $74(55.2)$ & $38(48.8)$ & $23(48.9)$ \\
\hline \multicolumn{4}{|l|}{ Diagnosis on MRI } \\
\hline No lesion or effusion, $n(\%)$ & $15(11.2)$ & $8(10.3)$ & $3(6.4)$ \\
\hline $\begin{array}{l}\text { Contusion (effusion with no ligament or } \\
\text { meniscal lesion), } \mathrm{n}(\%)\end{array}$ & $37(27.6)$ & $16(20.5)$ & $9(19.1)$ \\
\hline Medial collateral ligament lesion, n (\%) & $35(26.1)$ & $24(30.8)$ & $17(36.2)$ \\
\hline Lateral collateral ligament lesion, n (\%) & $8(6.0)$ & $6(7.7)$ & $4(8.5)$ \\
\hline Anterior cruciate ligament lesion, n (\%) & $28(20.9)$ & $20(25.6)$ & $12(25.5)$ \\
\hline Posterior cruciate ligament lesion, n (\%) & $6(4.5)$ & $2(2.6)$ & $1(2.1)$ \\
\hline Meniscal tear & $47(35.1)$ & $29(37.2)$ & $17(36.2)$ \\
\hline \multicolumn{4}{|l|}{ Knee symptoms } \\
\hline Sport activity as cause, $\mathrm{n}(\%)$ & $61(45.5)$ & $34(43.6)$ & $20(42.6)$ \\
\hline Knee pain NRS (0-10), mean \pm SD & $4.8 \pm 2.4$ & $4.6 \pm 2.5$ & $4.7 \pm 2.4$ \\
\hline Lysholm knee function score $(0-100)$, mean $\pm S D$ & $63.7 \pm 19.8$ & $62.2 \pm 20.7$ & $61.3 \pm 21.2$ \\
\hline
\end{tabular}


Table 2 Signs of osteoarthritis (OA; based on the KOSS scoring system) and presence of knee OA on the 6-year MRI, compared with the K\&L score for knee OA on the 6-year radiograph, their relation with the K\&L score (grade 0 vs grade 1 and 2) and their relation with persistent knee symptoms at 6-year follow-up $(n=47)$

\begin{tabular}{|c|c|c|c|c|c|c|}
\hline & & \multicolumn{3}{|c|}{ K\&L score on 6-year radiograph } & \multirow[b]{2}{*}{$\begin{array}{l}\text { K\&L score (grade } 0 \text { vs } 1 \\
\text { and } 2) \text { OR }(95 \% \mathrm{Cl})\end{array}$} & \multirow{2}{*}{$\begin{array}{l}\text { Persistent knee } \\
\text { symptoms OR } \\
(95 \% \mathrm{Cl})\end{array}$} \\
\hline & & $\begin{array}{l}\text { Grade } 0 \\
(n=28) n(\%)\end{array}$ & $\begin{array}{l}\text { Grade } 1 \\
(n=13) n(\%)\end{array}$ & $\begin{array}{l}\text { Grade } 2 \\
(n=6) n(\%)\end{array}$ & & \\
\hline Signs of $O A$ on 6-year MRI & \multicolumn{6}{|c|}{ Frequency $(n=47) n(\%)$} \\
\hline Chondral defect & $26(55.3)$ & $10(35.7)$ & $10(76.9)$ & $6(100.0)$ & $9.6(2.2 \text { to } 41.1)^{*}$ & $2.3(0.7$ to 8.4$)$ \\
\hline Medial & $22(46.8)$ & $6(21.4)$ & $10(76.9)$ & $6(100.0)$ & $19.6(4.2 \text { to } 90.2)^{*}$ & $1.8(0.5$ to 6.0$)$ \\
\hline Lateral & 15 (31.9) & 5 (17.9) & $5(38.5)$ & 5 (83.3) & $5.1(1.4 \text { to } 19.2)^{*}$ & $5.4(1.4 \text { to } 20.3)^{*}$ \\
\hline Osteophytes† & $21(44.7)$ & 7 (25.0) & $8(61.5)$ & $6(100.0)$ & $8.4(2.2 \text { to } 31.8)^{*}$ & $3.0(0.9$ to 10.6$)$ \\
\hline Medial & $19(40.4)$ & $5(17.9)$ & $8(61.5)$ & $6(100.0)$ & $12.9(3.2 \text { to } 52.6)^{*}$ & $4.1(1.1 \text { to } 14.6)^{*}$ \\
\hline Lateral & $13(27.7)$ & $4(14.3)$ & $4(30.8)$ & 5 (83.3) & $5.4(1.3 \text { to } 21.7)^{*}$ & 2.1 (0.6 to 7.7$)$ \\
\hline Subchondral cyst & $17(36.2)$ & $5(17.9)$ & $7(53.8)$ & $5(83.3)$ & $7.9(2.1 \text { to } 30.2)^{*}$ & $1.6(0.5$ to 5.7$)$ \\
\hline Medial & $11(23.4)$ & $2(7.1)$ & $5(38.5)$ & $4(66.7)$ & $11.7(2.1 \text { to } 63.8)^{*}$ & $1.9(0.5$ to 7.5$)$ \\
\hline Lateral & 7 (14.9) & $3(10.7)$ & $3(23.1)$ & $1(16.7)$ & $2.2(0.4$ to 11.3$)$ & $1.6(0.3$ to 8.0$)$ \\
\hline Bone marrow oedema & $19(40.4)$ & $7(25.0)$ & $8(61.5)$ & $4(66.7)$ & $5.1(1.5 \text { to } 18.2)^{*}$ & 1.8 (0.5 to 6.2$)$ \\
\hline Medial & $14(29.8)$ & $4(14.3)$ & $6(46.2)$ & $4(66.7)$ & $6.6(1.7 \text { to } 26.8)^{*}$ & 1.7 (0.5 to 6.3$)$ \\
\hline Lateral & 7 (14.9) & $3(10.7)$ & $3(23.1)$ & $1(16.7)$ & 2.2 (0.4 to 11.3$)$ & 3.1 (0.6 to 16.1$)$ \\
\hline Meniscal subluxation $\ddagger$ & $10(21.3)$ & $2(7.1)$ & $3(23.1)$ & $5(83.3)$ & $9.5(1.7 \text { to } 51.9)^{*}$ & $7.3(1.5 \text { to } 34.1)^{*}$ \\
\hline Medial & $10(21.3)$ & $2(7.1)$ & $3(23.1)$ & $5(83.3)$ & $9.5(1.7 \text { to } 51.9)^{*}$ & $7.3(1.5 \text { to } 34.1)^{*}$ \\
\hline Lateral & $0(0.0)$ & $0(0.0)$ & $0(0.0)$ & $0(0.0)$ & - & - \\
\hline Meniscal degeneration $\ddagger$ & 39 (83.0) & $21(75.0)$ & $12(92.3)$ & $6(100.0)$ & $6.0(0.7$ to -53.5$)$ & 4.4 (0.5 to 39.2$)$ \\
\hline Medial & $32(68.1)$ & $17(60.7)$ & $11(84.6)$ & $4(66.7)$ & 2.4 (0.6 to 9.3$)$ & $1.0(0.3$ to 3.8$)$ \\
\hline Lateral & $18(38.3)$ & $6(21.4)$ & 7 (53.8) & 5 (83.3) & $6.3(1.7 \text { to } 23.0)^{*}$ & 3.1 (0.9 to 11.0$)$ \\
\hline Effusion $\ddagger$ & $5(10.6)$ & $2(7.1)$ & $2(15.4)$ & $1(16.7)$ & 2.4 (0.4 to 16.2$)$ & $1.3(0.2$ to 8.9$)$ \\
\hline Baker's cyst & 5 (10.6) & 4 (14.2) & $1(7.7)$ & $0(0.0)$ & - & 2.0 (0.1 to 34.2$)$ \\
\hline Knee OA on 6-year MRI§ & $17(36.2)$ & $3(10.7)$ & $8(61.5)$ & $6(100.0)$ & $23.3(4.8 \text { to } 112)^{*}$ & $3.7(1.0 \text { to } 13.2)^{*}$ \\
\hline
\end{tabular}

had a significant relation with the self-reported persistent knee symptoms at 6-year follow-up (table 2).

At 6-year follow-up of the 47 patients, knee OA on MRI (according to the definition of Hunter et al) ${ }^{14}$ was present in 17 patients $(36.2 \%)$ and showed a strong significant relationship with the $\mathrm{K} \& \mathrm{~L}$ score on the 6-year radiograph (OR 23.3, 95\% CI 4.8 to 112). A significant relationship was also found with the reported persistent knee symptoms (table 2).

Table 3 presents a cross-tabulation of knee OA at baseline versus 6-year MRI. Of the 17 patients with knee OA at 6-year follow-up, $12(25.5 \%)$ showed new onset knee OA on 6-year MRI, 3 (6.4\%) showed progression of existing knee OA, and 2 patients $(4.3 \%)$ with existing knee OA showed no progression on 6-year MRI. Therefore, of the 42 patients with no knee OA at baseline, $12(28.6 \%)$ showed new knee OA at 6-year follow-up and, of the five patients with existing knee $\mathrm{OA}$ at baseline, $3(60.0 \%)$ showed progression.

\section{Prognostic factors}

Table 4 presents the pooled univariable associations between baseline characteristics and new onset knee OA or progression of existing knee OA at 6-year MRI.
Table 3 Cross-tabulation of knee $\mathrm{OA}$ at baseline versus the 6-year MRI

\begin{tabular}{lllll}
\hline & & \multicolumn{3}{c}{$\begin{array}{l}\text { Knee OA on } \\
\text { baseline MRI }\end{array}$} \\
\cline { 3 - 5 } & & No & Yes & Total \\
\hline Knee OA on & No & 30 & - & 30 \\
6-year MRI & Yes, new knee OA & 12 & - & 12 \\
& $\begin{array}{l}\text { Yes, stable existing } \\
\text { knee OA }\end{array}$ & - & 2 & 2 \\
& $\begin{array}{l}\text { Yes, progression } \\
\text { existing knee OA }\end{array}$ & - & 3 & 3 \\
& Total & 42 & 5 & 47 \\
\hline OA, osteoarthritis. & & & \\
& & & & \\
\end{tabular}

The patient characteristics age and female gender showed an association with progression or new onset knee OA at the 6-year follow-up $(p \leq 0.20)$. From the mechanism and symptom characteristics, trauma during sports, limitation during daily function and history of non-traumatic knee symptoms were associated $(p \leq 0.20)$.

From the baseline MRI findings, cartilage defect, osteophytes, bone marrow oedema and meniscal degeneration were associated $(\mathrm{p} \leq 0.20)$. 
Table 4 Univariable association between baseline characteristics and knee osteoarthritis (new or progression) on the 6-year MRI

\begin{tabular}{|c|c|c|c|}
\hline \multirow[b]{2}{*}{ Variable } & \multicolumn{3}{|c|}{ Univariable 6 year $(n=47)$} \\
\hline & Pooled OR & Pooled $95 \% \mathrm{Cl}$ & Pooled Sig \\
\hline \multicolumn{4}{|l|}{ Patient characteristics } \\
\hline Age & 1.10 & 1.02 to 1.18 & $0.01^{*}$ \\
\hline Female gender & 2.57 & 0.71 to 9.26 & $0.15^{\star}$ \\
\hline Body mass index & 1.03 & 0.87 to 1.23 & 0.71 \\
\hline \multicolumn{4}{|l|}{ Mechanism and symptom characteristics } \\
\hline Trauma during sport & 0.23 & 0.06 to 0.98 & $0.05^{\star}$ \\
\hline Pain (11-point scale) & 1.16 & 0.89 to 1.53 & 0.28 \\
\hline Limitation and pain during daily function (Lysholm <80) & 5.48 & 0.63 to 48.0 & $0.13^{*}$ \\
\hline Instability of the knee (Lysholm) & 0.49 & 0.12 to 1.93 & 0.31 \\
\hline History of traumatic knee symptoms & 1.04 & 0.28 to 3.87 & 0.95 \\
\hline History of non-traumatic knee symptoms & 4.26 & 1.09 to 16.7 & $0.04^{\star}$ \\
\hline \multicolumn{4}{|l|}{ MRI findings } \\
\hline Any lesion & 0.56 & 0.14 to 2.19 & 0.40 \\
\hline Anterior cruciate ligament tear & 0.64 & 0.15 to 2.81 & 0.55 \\
\hline Medial collateral ligament lesion & 1.27 & 0.36 to 4.51 & 0.71 \\
\hline Meniscal tear & 1.27 & 0.36 to 4.51 & 0.71 \\
\hline Chondral defect & 2.70 & 0.64 to 11.4 & $0.18^{*}$ \\
\hline Osteophytes & 10.0 & 1.71 to 58.4 & $0.01^{*}$ \\
\hline Bone marrow oedema & 3.11 & 0.73 to 13.2 & $0.12^{*}$ \\
\hline Meniscal degeneration & 0.38 & 0.10 to 1.49 & $0.17^{\star}$ \\
\hline
\end{tabular}

Table 5 Multivariable association between baseline characteristics and knee osteoarthritis (new or progression) on the 6-year MRI

\begin{tabular}{|c|c|c|c|}
\hline \multirow[b]{2}{*}{ Variable } & \multicolumn{3}{|c|}{ Multivariable 6 year $(n=47)$} \\
\hline & Pooled OR & Pooled $95 \% \mathrm{Cl}$ & Pooled Sig \\
\hline Age & 1.15 & 1.02 to 1.29 & 0.02 \\
\hline History of non-traumatic knee symptoms & 10.56 & 1.14 to 97.8 & 0.04 \\
\hline Bone marrow oedema & 6.89 & 0.83 to 57.3 & 0.07 \\
\hline
\end{tabular}

Table 5 presents the pooled multivariable associations between baseline characteristics and new onset knee OA or progression of existing knee OA at 6-year MRI. Age $(\mathrm{p}=0.02)$, history of non-traumatic knee symptoms $(p=0.04)$ and bone marrow oedema $(p=0.07)$ were independently related with progression or new onset knee $\mathrm{OA}$ at 6-year MRI.

\section{DISCUSSION}

\section{Degenerative abnormalities on 6-year MRI and radiography}

We found that most of the degenerative abnormalities on the 6-year MRI (according to the KOSS scoring system) were significantly related with the K\&L score on the 6-year radiograph. Only a few of the degenerative abnormalities on the 6-year MRI, that is, lateral cartilage defect(s), medial osteophyte(s) and medial meniscal subluxation, were significantly related with patients' reported persistent knee symptoms at 6-year follow-up. These results are largely in accordance with similar reports. $^{27-30}$ The main difference between our study and earlier studies is that we made a distinction between degenerative abnormalities in the medial and lateral knee compartment, because, in our population, degenerative abnormalities of the medial femorotibial joint compartment were more common than those of the lateral compartment.

\section{Knee $\mathrm{OA}$ on the 6-year MRI and related prognostic factors}

In this study, $32.0 \%$ of the patients showed new onset knee OA or progression of existing knee OA on the MRI, 6 years after trauma. This percentage is somewhat higher compared with our 1-year results, where $23.1 \%$ of the patients showed new onset knee OA or progression of existing knee OA on 1-year MRI. ${ }^{8}$ This also means that in about $70 \%$ of the patients with new onset knee OA or progression of existing knee OA at 6-year follow-up, this was already present at 1-year follow-up.

Therefore, the majority of patients appears to develop within the first year after knee trauma a new onset knee OA or progression of existing knee OA. 


\section{Strengths and limitations}

The present study has several limitations. Only a small number of patients were eventually investigated because a relatively large percentage was lost to follow-up. Also, only about $60 \%$ of the patients available at 6-year follow-up were willing to undergo a radiograph and MRI of their knee. However, patients lost to follow-up and patients not willing to undergo additional radiography and MRI of their knee did not appear to be a selected group of patients.

Although the definition we used for knee OA on MRI (according to Hunter et al) ${ }^{14}$ has not been validated, it appears to be the best available definition at this moment. In our data set, the definition showed a strong relationship with the $\mathrm{K} \& \mathrm{~L}$ score on 6-year follow-up.

\section{Comparison with existing literature}

In the present study, age, history of non-traumatic knee symptoms and bone marrow oedema on baseline MRI were independently related with progression or new onset knee OA 6 years after knee trauma. This concurs with other reports, in which age and bone marrow oedema were also prognostic factors for the onset or progression of knee OA. ${ }^{34} 8-11$

It is noteworthy that, in the present study, no relationship was found between body mass index (BMI) and progressive or new onset knee OA, despite BMI is an established risk factor for knee OA. ${ }^{3} 4931$ This relationship was also absent in our 1-year follow-up study on the development of knee OA. ${ }^{8}$ Also, we found no significant association between meniscal lesions/cruciate ligament lesions and progression or new knee OA, whereas other studies have suggested that these lesions are related with knee OA. ${ }^{9} 3233$

This might be explained by our small sample size (and resulting lack of power), and our primary care setting where severity of traumatic knee symptoms is expected to be lower than in studies performed in secondary care.

\section{Implications for research and/or practice}

Clinicians need to be aware of the occurrence of knee $\mathrm{OA}$ in patients after knee trauma, and check for a history of non-traumatic knee symptoms and bone marrow oedema on initial MRI. Additional studies are needed to confirm our results and to investigate how to prevent the development of new knee OA or progression of existing knee OA in these high-risk patients.

\section{CONCLUSIONS}

Degenerative knee abnormalities on MRI are related to the K\&L score; however, not all abnormalities are reflected in clinical outcome. Age, history of non-traumatic knee symptoms and bone marrow oedema predict knee OA 6 years after knee trauma, present in $32 \%$ of the patients.

Contributors BWK, SMAB-Z and EHGO substantially contributed to conception and design of the study. MK, PAJL, IMK, DV and EHGO were involved in acquisition of data. MK, PAJL, EHGO and SMAB-Z were involved in the analysis and interpretation of data and in drafting the manuscript. All authors revised the draft manuscript critically and have read and approved the final manuscript.

Funding This work was supported by the Department of General Practice of the Erasmus MC Rotterdam; Anna Foundation and the insurance companies TRIAS, Zilveren Kruis, Achmea and $0 Z$.

Competing interests None declared.

Patient consent Obtained.

Ethics approval The study protocol was approved by the Institutional Review Board of Erasmus MC University Medical Center Rotterdam.

Provenance and peer review Not commissioned; externally peer reviewed.

Data sharing statement Patients did not give informed consent for data sharing, but the data are anonymised and the risk of identification is low. Data from the trial may be available from the corresponding author at $p$. luijsterburg@erasmusmc.nl, subject to agreement about the use of the data.

Open Access This is an Open Access article distributed in accordance with the Creative Commons Attribution Non Commercial (CC BY-NC 4.0) license, which permits others to distribute, remix, adapt, build upon this work noncommercially, and license their derivative works on different terms, provided the original work is properly cited and the use is non-commercial. See: http:// creativecommons.org/licenses/by-nc/4.0/

\section{REFERENCES}

1. van der Linden M, Westert G, de Bakker D, Schellevis F. [Second National Dutch Study: complaints and disorders in general practice] (in Dutch). Utrecht/Bilthoven: The Netherlands Institute for Health Services Research (NIVEL) 2004;1-136.

2. Wagemakers HP, Luijsterburg PA, Heintjes EM, et al. Outcome of knee injuries in general practice: 1-year follow-up. Br J Gen Pract 2010;60:56-63.

3. Blagojevic M, Jinks C, Jeffery A, et al. Risk factors for onset of osteoarthritis of the knee in older adults: a systematic review and meta-analysis. Osteoarthr Cartil 2010;18:24-33.

4. Cooper C, Snow S, McAlindon TE, et al. Risk factors for the incidence and progression of radiographic knee osteoarthritis. Arthritis Rheum 2000;43:995-1000.

5. Englund $M$. The role of biomechanics in the initiation and progression of OA of the knee. Best Pract Res Clin Rheumatol 2010;24:39-46.

6. Gelber AC, Hochberg MC, Mead LA, et al. Joint injury in young adults and risk for subsequent knee and hip osteoarthritis. Ann Intern Med 2000;133:321-8.

7. Brooks PM. The burden of musculoskeletal disease-a global perspective. Clin Rheumatol 2006;25:778-81.

8. Koster MI, Oei EH, Hensen JH, et al. Predictive factors for new onset or progression of knee osteoarthritis one year after trauma: MRI follow-up in general practice. Eur Radiol 2011;21:1509-16.

9. Lohmander LS, Englund PM, Dahl LL, et al. The long-term consequence of anterior cruciate ligament and meniscus injuries: osteoarthritis. Am J Sports Med 2007;35:1756-69.

10. Felson DT, McLaughlin S, Goggins J, et al. Bone marrow edema and its relation to progression of knee osteoarthritis. Ann Intern Med 2003;139:330-6.

11. Libicher M, Ivancic M, Hoffmann M, et al. Early changes in experimental osteoarthritis using the Pond-Nuki dog model: technical procedure and initial results of in vivo MR imaging. Eur Radiol 2005;15:390-4.

12. Bedson J, Croft PR. The discordance between clinical and radiographic knee osteoarthritis: a systematic search and summary of the literature. BMC Musculoskelet Disord 2008;9:116.

13. Hunter DJ, Zhang W, Conaghan PG, et al. Responsiveness and reliability of MRI in knee osteoarthritis: a meta-analysis of published evidence. Osteoarthr Cartil 2011;19:589-605.

14. Hunter DJ, Arden N, Conaghan PG, et al. Definition of osteoarthritis on MRI: results of a Delphi exercise. Osteoarthr Cartil 2011;19:963-9.

15. Heintjes EM, Berger MY, Koes BW, et al. Knee disorders in primary care: design and patient selection of the HONEUR knee cohort. BMC Musculoskelet Disord 2005;6:45.

16. Bengtsson J, Mollborg J, Werner S. A study for testing the sensitivity and reliability of the Lysholm knee scoring scale. Knee Surg Sports Traumatol Arthrosc 1996;4:27-31. 
17. Kocher MS, Steadman JR, Briggs KK, et al. Reliability, validity, and responsiveness of the Lysholm knee scale for various chondral disorders of the knee. J Bone Joint Surg Am 2004;86-A:1139-45.

18. Tegner $Y$, Lysholm J. Rating systems in the evaluation of knee ligament injuries. Clin Orthop Relat Res 1985;198:43-9.

19. Hoppenfield S. Physical examination of the spine and extremities. East Norwalk Conn: Appleton Century Crofts, 1976.

20. Reider B. The orthopaedic physical examination. Philadelphia (PA): WB Saunders, 1999:202-45.

21. Kornaat PR, Ceulemans RY, Kroon HM, et al. MRI assessment of knee osteoarthritis: Knee Osteoarthritis Scoring System (KOSS)inter-observer and intra-observer reproducibility of a compartment-based scoring system. Skeletal Radiol 2005;34:95-102.

22. Kellgren JH, Lawrence JS. Radiological assessment of osteo-arthrosis. Ann Rheum Dis 1957;16:494-502.

23. Mallen $C D$, Peat G, Thomas $\mathrm{E}$, et al. Prognostic factors for musculoskeletal pain in primary care: a systematic review. $\mathrm{Br} J \mathrm{Gen}$ Pract 2007;57:655-61.

24. Donders AR, van der Heijden GJ, Stijnen T, et al. Review: a gentle introduction to imputation of missing values. $J$ Clin Epidemiol 2006;59:1087-91.

25. Moons KG, Donders RA, Stijnen T, et al. Using the outcome for imputation of missing predictor values was preferred. J Clin Epidemiol 2006;59:1092-101.

26. van der Heijden GJ, Donders AR, Stijnen T, et al. Imputation of missing values is superior to complete case analysis and the missing-indicator method in multivariable diagnostic research: a clinical example. J Clin Epidemiol 2006;59:1102-9.

27. Link TM, Steinbach LS, Ghosh S, et al. Osteoarthritis: MR imaging findings in different stages of disease and correlation with clinical findings. Radiology 2003;226:373-81.

28. Phan CM, Link TM, Blumenkrantz G, et al. MR imaging findings in the follow-up of patients with different stages of knee osteoarthritis and the correlation with clinical symptoms. Eur Radiol 2006;16:608-18.

29. Hayes CW, Jamadar DA, Welch GW, et al. Osteoarthritis of the knee: comparison of MR imaging findings with radiographic severity measurements and pain in middle-aged women. Radiology 2005;237:998-1007.

30. Kornaat PR, Bloem JL, Ceulemans RY, et al. Osteoarthritis of the knee: association between clinical features and MR imaging findings. Radiology 2006;239:811-17.

31. Jiang L, Tian W, Wang $Y$, et al. Body mass index and susceptibility to knee osteoarthritis: a systematic review and meta-analysis. Joint Bone Spine 2012;79:291-7.

32. Berthiaume MJ, Raynauld JP, Martel-Pelletier J, et al. Meniscal tear and extrusion are strongly associated with progression of symptomatic knee osteoarthritis as assessed by quantitative magnetic resonance imaging. Ann Rheum Dis 2005;64:556-63.

33. Sharma L, Eckstein F, Song J, et al. Relationship of meniscal damage, meniscal extrusion, malalignment, and joint laxity to subsequent cartilage loss in osteoarthritic knees. Arthritis Rheum 2008;58:1716-26. 